\title{
A lucky and reversible cause of 'ischaemic bowel'
}

\author{
YF Shea *, Felix CL Chow, F Chan, Janice JK Ip, Patrick KC Chiu, Fion SY Chan, LW Chu
}

\section{A B S T R A C T}

An 81-year-old man was admitted with an infective exacerbation of chronic obstructive pulmonary disease. He also had clinical and radiological features suggestive of ileus. On day 6 after admission, he developed generalised abdominal pain. Urgent computed tomography of the abdomen showed presence of portovenous gas and dilated small bowel with pneumatosis intestinalis and whirl sign. Emergency laparotomy was performed, which showed a 7-mm perforated ulcer over the first part of the duodenum and small bowel volvulus. Omental patch repair and reduction of small bowel volvulus were performed. No bowel resection was required. The patient had a favourable outcome. Clinicians should suspect small bowel volvulus as a cause of ischaemic bowel. Presence of portovenous gas and pneumatosis intestinalis are normally considered to be signs of frank ischaemic bowel. The absence of bowel ischaemia at laparotomy in this patient shows that this is not necessarily the case and prompt surgical treatment could potentially save the bowels and lives of these patients.

\section{Hong Kong Med J 2015;21:471-4}

DOI: $10.12809 / \mathrm{hkmj} 144306$

${ }^{1}$ YF Shea *, MRCP, FHKAM (Medicine)

${ }^{2}$ FCL Chow, MB, BS, MRCS

${ }^{1} \mathrm{~F}$ Chan, MRCP, FHKAM (Medicine)

${ }^{3} \mathrm{JJK}$ Ip, MB, BS, FRCR

${ }^{1}$ PKC Chiu, FRCP(Glasg), FHKAM (Medicine)

${ }^{2}$ FSY Chan, FRCS, FHKAM (Surgery)

${ }^{1}$ LW Chu, MD, FRCP

1 Acute Geriatric Unit, Grantham Hospital, Aberdeen, Hong Kong

2 Department of Surgery, Queen Mary Hospital, The University of Hong Kong, Pokfulam, Hong Kong

${ }^{3}$ Department of Radiology, Queen Mary Hospital, The University of Hong Kong, Pokfulam, Hong Kong

* Corresponding author: elphashea@gmail.com

\section{Introduction}

Ischaemic bowel is often associated with high mortality. Common causes of ischaemic bowel include atrial fibrillation with arterial embolism, incarcerated hernia, volvulus, profound shock, and vasculitis. Volvulus in adults most often occurs in the colon and sigmoid colon (70-80\%), and less commonly in caecum (10-20\%). ${ }^{1}$ Small bowel volvulus (SBV) is rarely encountered in adults. ${ }^{1-9}$ Intra-operatively, if gangrenous small bowel is found, it needs to be resected and may potentially cause long-term complications, including short bowel syndrome. ${ }^{2}$ We report on a patient with primary SBV associated with a perforated duodenal ulcer (PDU), but the patient had a favourable outcome without the need for bowel resection, thereby avoiding the long-term complications associated with extensive bowel resection.

\section{Case report}

In February 2014, an 81-year-old man was admitted with an infective exacerbation of chronic obstructive pulmonary disease caused by influenza B virus. He had a history of left inguinal hernia repair. On admission, he had a temperature of $38^{\circ} \mathrm{C}$. He was tachypnoeic with diffuse expiratory wheeze on chest auscultation. His abdomen was slightly distended and bowel sounds were sluggish. There was no recurrence of the hernia. Complete blood count showed leukocytosis $\left(23.7 \times 10^{9} / \mathrm{L}\right.$ [reference range, $\left.\left.4.5-11.0 \times 10^{9} / \mathrm{L}\right]\right)$ and a haemoglobin level of $109 \mathrm{~g} / \mathrm{L}$ (reference range, 140-175 g/L). Liver and renal function tests and electrolytes were normal. Chest radiograph showed hyperinflation of the lungs with no consolidation. Abdominal radiograph showed dilated small bowel without air-fluid level.

The patient was treated with inhaled bronchodilators (albuterol 4 puffs every 4 hours and ipratropium bromide 2 puffs every 4 hours) and intravenous amoxicillin-clavulanate $1.2 \mathrm{~g}$ every 8 hours for 6 days. The dilated small bowel was initially attributed to ileus and the patient was kept nil-bymouth. Daily abdominal radiograph did not reveal any worsening of the small bowel dilatation. He developed an episode of fast atrial fibrillation on day 2 , which was controlled with amiodarone (initially with intravenous loading and infusion, then followed by $200 \mathrm{mg}$ orally twice a day). Flatus and bowel opening returned on day 5 and diet was resumed. On day 6 , the patient developed generalised abdominal pain. His abdomen was distended with no localised tenderness, but bowel sounds were absent. Arterial blood gas showed no metabolic acidosis. Computed tomography (CT) of the abdomen with contrast showed presence of portovenous gas, dilated small bowel with pneumatosis intestinalis, and whirl sign (Fig 1). 


\section{$\ulcorner$ 缺血性腸病」的一個幸運和可逆性病因} 佘日峯、周祉樂、陳飛、葉精勤、趙嘉俊、陳小燕、朱亮榮 一名 81 歲男子因其慢性阻塞性肺病有感染加劇的跡象而入院。臨床及 影像學亦顯示他同時患有腸梗阻。病人入院後第 6 天出現腹痛。緊急 腹部電腦斷層影像顯示門靜脈積氣, 以及小腸擴張併腸壁積氣和漩渦 徵。緊急剖腹術發現十二指腸的首部分有直徑 7 毫米的潰瘍穿孔, 並 有小腸扭轉。為病人進行大網膜補片修補和減少小腸扭轉, 並母須切 除晹藏, 病人最後順利康復。臨床醫生如遇上病人有缺血性腸病, 應 考慮小腸扭轉的病因。門靜脈積氣和腸壁積氣一般被認為是缺血性腸 病的病徵。不過, 上述患者剖腹時並未發現缺血性腸病, 顯示門靜脈 和腸壁積氣並不一定代表有缺血性腸病。為患者及時進行手術不但能 避免腸切除, 更可助挽回生命。
Emergency laparotomy was performed that showed a 7-mm perforated ulcer over the first part of the duodenum, which was sealed off by the adjacent liver and falciform ligament. The small bowel was grossly distended. There was SBV with twisting of the small bowel along the root of the mesentery by $180^{\circ}$ with mild dusky appearance. Omental patch repair of the duodenal ulcer and reduction of the SBV were performed. Small bowel perfusion improved significantly and a strong superior mesenteric artery pulse was confirmed. Bowel resection was not required. Histological examination of the duodenal ulcer showed no evidence of Helicobacter pylori infection. Repeated $\mathrm{CT}$ of the abdomen on day 8 showed resolution of portovenous gas (Fig 2). Postoperatively, the patient had the complication of an intra-abdominal abscess, which was managed successfully by percutaneous drainage and systemic antibiotics (vancomycin $500 \mathrm{mg}$ daily and meropenem $1 \mathrm{~g}$ every 12 hours intravenously for 2 weeks followed by levofloxacin $500 \mathrm{mg}$ orally daily for 1 week). He was discharged on day 36.

\section{Discussion}

The initial clinical feature of dilated small bowel with sluggish bowel sound in the background of an infective exacerbation of chronic obstructive pulmonary disease was interpreted as being caused by paralytic ileus. ${ }^{10}$ With the sudden worsening in abdominal pain and the presence of paroxysmal atrial fibrillation, the possibility of ischaemic bowel was reconsidered. This explains why SBV was only diagnosed by CT of the abdomen on day 6 after admission. Small bowel volvulus refers to the twisting of a small bowel segment around the axis of its own mesentery. In the elderly patients, a secondary type with an underlying cause is most commonly encountered. ${ }^{3}$ These secondary causes include tumours, mesenteric lymph nodes, adhesions after previous surgery, malrotation, congenital bands, intussusception, colostomy, and

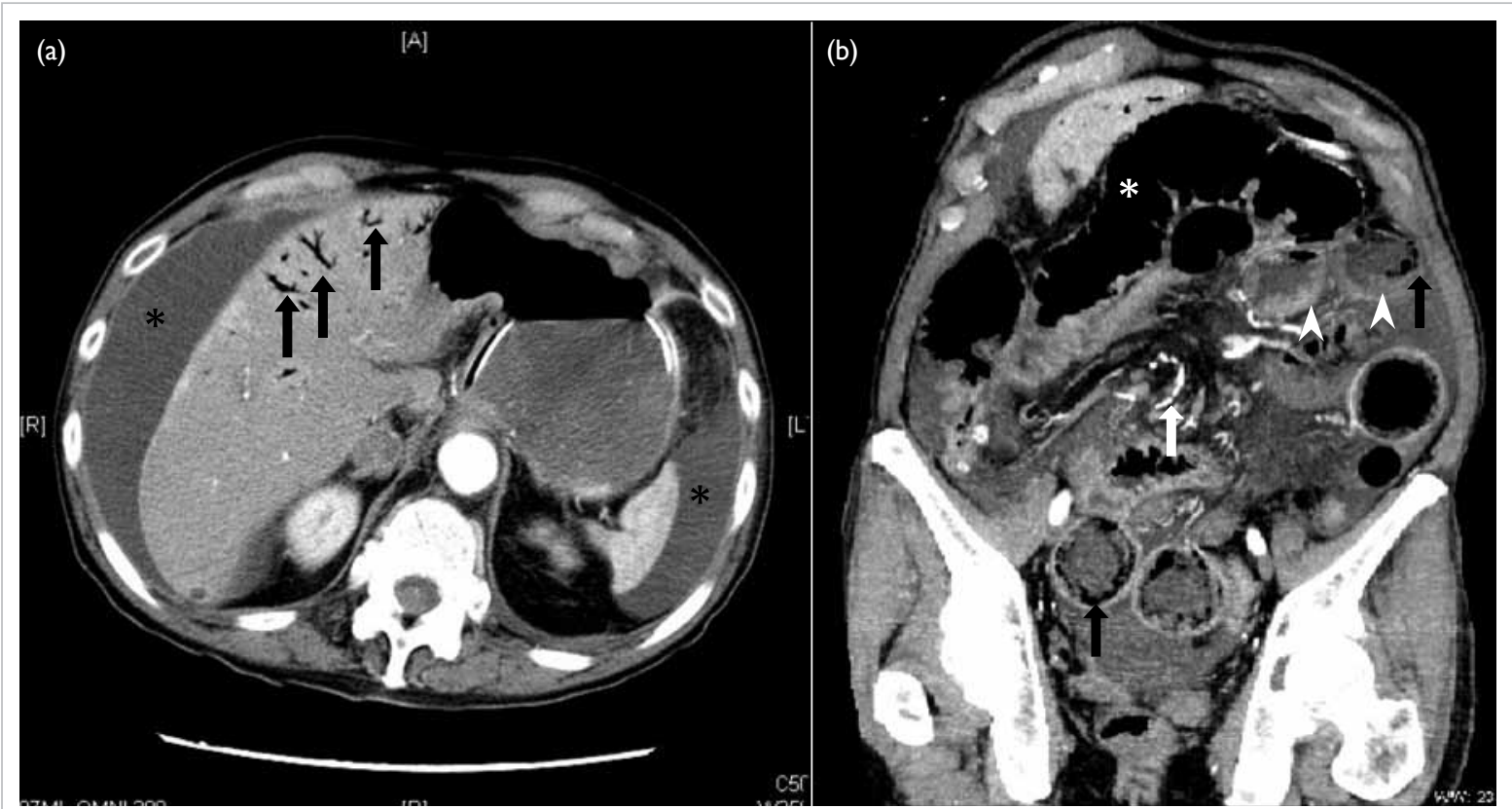

FIG I. Computed tomography images of the abdomen with contrast on day 6

(a) Axial view showing portovenous gas in the hepatic parenchyma (arrows) and ascites (asterisks); and (b) coronal view showing the whirl sign (white arrow) with mesentery appearing as a whirl-like pattern twisting around the axis of the superior mesenteric artery with small bowel dilatation (asterisk), pneumatosis intestinalis (black arrow), bowel wall oedema (white arrowheads) and impairment in bowel wall enhancement 

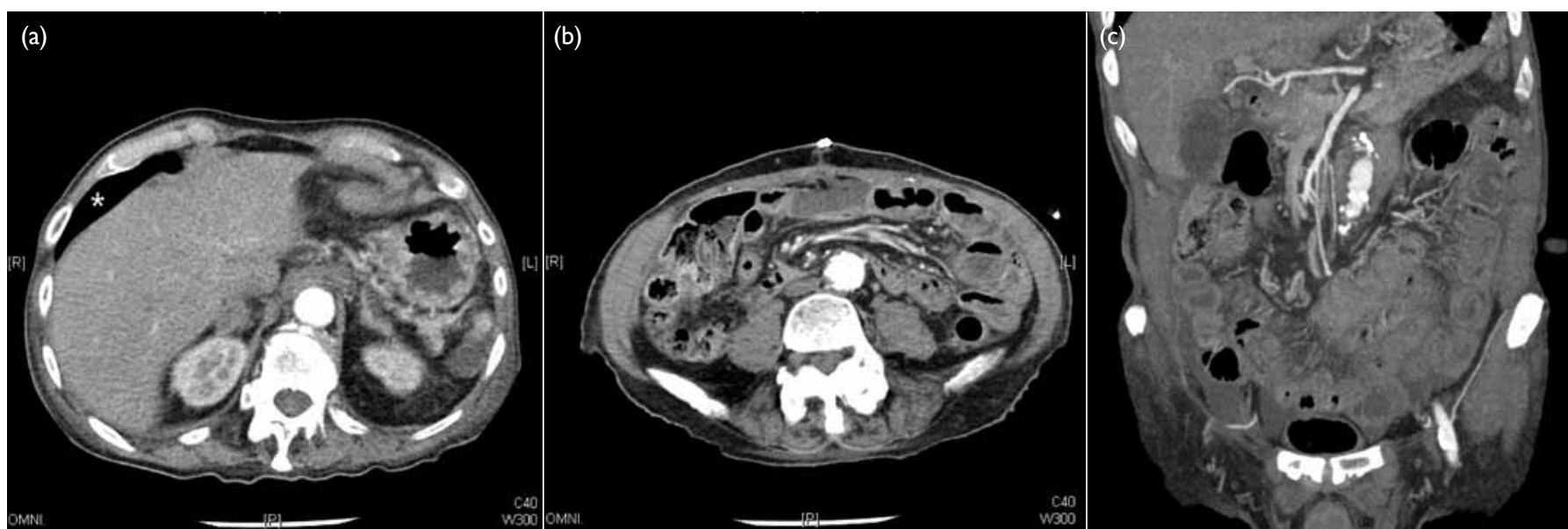

FIG 2. Computed tomography images of the abdomen with contrast 8 days after operation

(a) Axial view showing resolution of portovenous gas in the hepatic parenchyma and postoperative pneumoperitoneum (asterisk); (b) axial view showing resolution of the whirl sign and small bowel obstruction; and (c) coronal view showing untwisted mesentery

internal hernias. ${ }^{3}$ If no underlying cause is found, as in this patient, the SBV is considered to be a primary SBV (some surgeons may regard malrotation and congenital adhesions as primary SBV). ${ }^{3,4}$ There are certain risk factors that have been linked to primary SBV, including long mobile mesentery, short mesenteric base, long small bowel, and consumption of a large amount of fibre-rich food after prolonged fasting, with overloading of an empty intestine. . $^{1,3,6}$ With torsion of the small bowel and its mesentery, the superior mesenteric arterial blood supply is compromised, which results in bowel infarction that usually occurs within 6 hours. ${ }^{3}$

The most important clinical feature is persistent abdominal pain with absence of bowel sounds on physical examination. ${ }^{1-9}$ Plain abdominal radiography is of limited diagnostic value. ${ }^{4}$ Abdominal CT is the most useful tool for obtaining the correct preoperative diagnosis. ${ }^{4}$ The findings on $\mathrm{CT}$ of the abdomen reflect the underlying pathophysiology of the SBV. Whirl sign, which refers to the twisting of mesentery around the origin of the torsion, is the most typical radiological sign of SBV..$^{4,7-9}$ Alternatively, a venous cut-off sign, referring to the occlusion of the superior mesenteric vein, may also be found. 9 With lymphatic and venous occlusions, there will be small bowel wall oedema and thickening. ${ }^{4}$ Small bowel dilatation is caused by intestinal obstruction resulting from the torsion. ${ }^{4}$ The bowel wall ischaemia results from the pneumatosis intestinalis and portovenous gas. ${ }^{4}$ It has been proposed that with intestinal ischaemia, the gas produced by gas-forming organisms accumulates in the bowel wall (pneumatosis intestinalis) and circulates to the liver (portovenous gas); alternatively the gas-producing organisms may enter the portal circulation and produce the gas there (portovenous gas). ${ }^{11}$

The causal relationship between SBV and PDU in this patient is not well established. We suspected that both the SBV and a non-PDU might be present during the early phase of admission. The resumption of a meal after a period of fasting exacerbated the volvulus. It has been proposed that the transit of food contents into the empty proximal jejunum could cause a gravitational migration of this segment into the left lower quadrant; forcing the distal empty bowel loops in a clockwise direction to the right upper quadrant with torsion of the mesentery. ${ }^{6}$ The mechanical obstruction contributes to the perforation of the duodenal ulcer which was a weak point and, together with the impending bowel ischaemia, led to the generalised abdominal pain. The possibility of ileus converting into SBV was less likely because of the usually reversible nature of ileus with treatment of the infection.

A favourable outcome for patients with SBV depends on prompt emergency laparotomy. ${ }^{1-9}$ The absence of bowel gangrene intra-operatively predicted a favourable outcome for this patient. Strictly, volvulus is defined by more than $180^{\circ}$ of rotation, so the intra-operative finding of small bowel twisting around the mesentery root by $180^{\circ}$ may signify that the SBV was in the process of partially reversing by itself. In one case series involving 19 patients, Ruiz-Tovar et $\mathrm{al}^{6}$ noted $100 \%$ mortality in patients with an intra-operative finding of bowel wall gangrene. Birnbaum et $\mathrm{al}^{3}$ also reported the use of enteropexy to prevent recurrence of primary SBV in a 69-year-old man with long mobile mesentery.

In summary, clinicians should suspect SBV as a cause of ischaemic bowel. Presence of portovenous 
gas and pneumatosis intestinalis are normally considered signs of frank ischaemic bowel. The absence of bowel infarction in this patient illustrates that this is not necessarily the case and prompt surgical treatment could potentially save the bowels and lives of these patients.

\section{References}

1. Kim KH, Kim MC, Kim SH, Park KJ, Jung GJ. Laparoscopic management of a primary small bowel volvulus: a case report. Surg Laparosc Endosc Percutan Tech 2007;17:3358.

2. Rubio PA, Galloway RE. Complete jejunoileal necrosis due to torsion of the superior mesenteric artery. South Med J 1990;83:1482-3.

3. Birnbaum DJ, Grègoire E, Campan $P$, Hardwigsen J, Le Treut YP. Primary small bowel volvulus in adult. J Emerg Med 2013;44:e329-30.

4. Jaramillo D, Raval B. CT diagnosis of primary small-bowel volvulus. AJR Am J Roentgenol 1986;147:941-2.

5. Weledji EP, Theophile N. Primary small bowel volvulus in adults can be fatal: a report of two cases and brief review of the subject. Trop Doct 2013;43:75-6.

6. Ruiz-Tovar J, Morales V, Sanjuanbenito A, Lobo E, Martinez-Molina E. Volvulus of the small bowel in adults. Am Surg 2009;75:1179-82.

7. $\mathrm{Li} \mathrm{CH}$, Chen $\mathrm{CH}$, Chou JW. Intestinal obstruction caused by small bowel volvulus. Am J Med 2011;124:e3-4.

8. Huang YM, Wu CC. Whirl sign in small bowel volvulus. BMJ Case Rep 2012;2012:bcr2012006688.

9. Ho YC. "Venous cut-off sign" as an adjunct to the "whirl sign" in recognizing acute small bowel volvulus via CT scan. J Gastrointest Surg 2012;16:2005-6.

10. Batke M, Cappell MS. Adynamic ileus and acute colonic pseudo-obstruction. Med Clin North Am 2008;92:64970,ix.

11. Abboud B, El Hachem J, Yazbeck T, Doumit C. Hepatic portal venous gas: physiopathology, etiology, prognosis and treatment. World J Gastroenterol 2009;15:3585-90. 